\title{
Characterization of Hydrated Cement Treated Crushed Rock Base (HCTCRB) as a Road Base Material in Western Australia
}

\author{
P. Jitsangiam, ${ }^{1}$ H. R. Nikraz ${ }^{2}$, and K.Siripun ${ }^{3}$ \\ ${ }^{1}$ Lecturer, Department of Civil Engineering, Curtin University of Technology, P.O. Box U1987, Perth, \\ WA, Australia 9845; PH (61) 8 9266-4527; FAX (61) 9266-2681; $\quad$ e-mail: \\ p.jitsangiam@curtin.edu.au; \\ ${ }^{2}$ Professor, Department of Civil Engineering, Curtin University of Technology, P.O. Box U1987, \\ Perth, WA, Australia 9845; PH (61) 8 9266-7609; FAX (61) 9266-2681; $\quad$ e-mail: \\ h.nikraz@curtin.edu.au ; \\ ${ }^{3} \mathrm{PhD}$ candidate, Department of Civil Engineering, Curtin University of Technology, P.O. Box \\ U1987, Perth, WA, Australia 9845; e-mail:komsun.siripun@postgrad.curtin.edu.au
}

\begin{abstract}
Hydrated Cement Treated Crushed Rock Base (HCTCRB) is widely used as a base course material for Western Australian roads. HCTCRB has been designed and used based on an empirical approach and practical experience, respectively, but those are not capable of explaining behavior of HCTCRB. Presently, a mechanistic approach becomes more reliable in pavement design and analysis and behavior of pavements can be more understood. Consequently, characterization of HCTCRB following the mechanistic approach is necessary. This study aimed to analyze the results of laboratory testing so as to assess the mechanical characteristics of HCTCRB. Conventional triaxial tests and repeated load triaxial tests (RLT tests) were performed. Factors, which would affect the performance of HCTCRB such as hydration periods and the amount of water added, were also investigated.
\end{abstract}

\section{INTRODUCTION}

Crushed rock with the addition of 2\% General Purpose (GP) Portland Cement, known as Hydrated Cemented Treated Crushed Rock Base (HCTCRB), is commonly used as a base course material for Western Australian roads. Understanding HCTCRB with respect to shear strength, resilient modulus, and permanent characteristics is important because if these characteristics are wellunderstood, pavement analysis and design can be done more precisely than in the past.

In practice, a large volume of HCTCRB is usually produced daily and then, kept in stockpiles waiting for an appropriate hydration period. It is difficult to maintain the same hydration period and to fix the appropriate amount of water added to produce HCTCRB. Furthermore, there are some doubts about the effect of hydration periods and amount of water added on the material's performance. Both factors need to be investigated to obtain more effective use of HCTCRB. 
This study aimed to analyze shear strength parameters, the resilient modulus, and the permanent deformation of HCTCRB, to report on these characteristics, and to investigate the effect of hydration periods and added water on the performance of HCTCRB so that a better understanding may be gained of the use of the material.

\section{EXPERIMENTAL PROGRAM}

\section{Materials}

Hydrated Cemented Treated Crushed Rock Base (HCTCRB)

Hydrated cemented treated crushed rock base (HCTCRB) is made by blending $2 \%$ cement, General Purpose (GP) or Portland cement following the AS 3972-1977 standard (Australian Standard AS 3972-1997 1997; MAIN ROADS Western Australia 1997), with a standard crushed rock base (MAIN ROADS Western Australia 2003). HCTCRB is mixed and stockpiled with an optimum moisture content in the range of $-1.0 \%$ to $+2.0 \%$ of the untreated crushed rock base as obtained by the MRWA Test Method WA 133.1(MAIN ROADS Western Australia 1997) during the initial 7-day hydration period.

\section{Laboratory program and testing}

The fresh crushed rock and HCTCRB ( the fresh crushed rock with 2\% cement by dry weight) were initially tested in terms of the compaction test in accordance with the MRWA Test Method WA 133.1(MAIN ROADS Western Australia, 2006) to establish the compaction curves for determining their optimum moisture content (OMC). HCTCRB samples for Repeated Load Triaxial (RLT) tests then were then made at $100 \%, 90 \%$, and $80 \%$ OMC of HCTCRB at varying hydration periods of 7 days, 14 days, and 30 days.

The test program consisted of both static and RLT tests. The static tests were carried out to establish the cohesion, $\mathrm{c}$, and the internal friction angle, $\phi$, of HCTCRB at the value of $100 \% \mathrm{OMC}$ at a 7 -day hydration period and a 28 -day curing time which included establishing the Mohr-Coulomb failure envelope. Repeated loading tests were performed to establish the relationships between the applied stress conditions and the resilient modulus values and the permanent deformation behavior of HCTCRB.

\section{Specimen preparation}

All of HCTCRB samples tested were prepared based upon $100 \%, 90 \%$, and $80 \% \mathrm{OMC}$ of HCTCRB. The mixing procedure entailed adding $2 \%$ GP cement (dry mass) to the wet crushed rock with the conditions of the $100 \%, 90 \%$, and $80 \%$ OMC of HCTCRB and then mixing each batch in the mixing machine for at least 10 minutes or until the mixture became uniform in color and texture. The mixture was then kept at room temperature in sealed plastic bags for periods of 7 days, 14 days, and 30 days. After that, for a mixture of a particular OMC and hydration period, it was then re-mixed in the same mixing machine for at least 10 minutes. The compaction processes were then carried out, using a modified compaction method in the standard mould $100 \mathrm{~mm}$ in diameter and $200 \mathrm{~mm}$ in height. Compaction was achieved with 25 blows of a $4.9 \mathrm{~kg}$ rammer at a $450 \mathrm{~mm}$ drop height in 8 layers. The specimens were kept in the mould and wrapped for 28 days to prevent loss of moisture. 


\section{Static triaxial tests}

Drained triaxial compression tests were conducted to determine the shear strength parameters ( $\mathrm{c}$ and $\phi$ ) of HCTCRB. Only specimens at the $100 \% \mathrm{OMC}$ condition of the 7-day hydration period and the 28-day curing time were tested under unsaturated conditions based on the HCTCRB standard and suctions were not measured during triaxial testing. In these tests, the specimen response was measured at three different constant confining pressures: $50 \mathrm{kPa}, 100 \mathrm{kPa}$, and $150 \mathrm{kPa}$ (see Table 1) using the same triaxial equipment and system for the measurement of resilient modulus and permanent deformation.

Table 1 Characteristics of the static triaxial tests on HCTCRB.

\begin{tabular}{|c|c|c|c|c|}
\hline Test & $\begin{array}{c}\text { Confining pressure } \\
(\mathrm{kPa})\end{array}$ & $\begin{array}{c}\text { Wet unit weight } \\
\left(\text { ton } / \mathrm{m}^{3}\right)\end{array}$ & $\begin{array}{c}\text { Dry unit weight } \\
\left(\text { ton } / \mathrm{m}^{3}\right)\end{array}$ & $\begin{array}{c}\text { Water content* } \\
(\%)\end{array}$ \\
\hline 1 & 50 & 2.22 & 2.12 & 4.52 \\
2 & 100 & 2.19 & 2.09 & 4.64 \\
3 & 150 & 2.19 & 2.10 & 4.48 \\
\hline
\end{tabular}

* Water content of the sample after the hydration period of 7 days.

\section{Resilient modulus tests and permanent deformation tests}

The standard method of the Austroads APRG 00/33-2000 (Voung \& Brimble, 2000) for the Repeated Load Triaxial Test Method was followed for the resilient modulus tests and the permanent deformation tests. The UTM-14P digital servo control testing machine which has the ability to conduct resilient modulus tests and permanent deformation tests was used in the Geomechanics Laboratory, Department of Civil Engineering, Curtin University of Technology.

New specimens were prepared, as described in the previous section. Permanent deformation testing was performed. In this testing, the specimens were loaded with three stress stages at the ratios of the dynamic deviator stress, $\sigma_{d}$ to the static confining stress, $\sigma_{3}$ as 350 to 150,450 to 150 , and 550 to 150 , respectively, each involving 10,000 cycles with the rate of the dynamic deviator stress at $1 / 3 \mathrm{~Hz}$ of rectangular pulse loading for each particular stress condition.

After permanent deformation tests, in accordance with the above standard, the same specimens were immediately subjected to resilient modulus test applied sequentially by the difference of the 65 stress stages. The objective of the test is to check the elastic condition of each specimen throughout the multiple loading stress stages. This process simulates the real traffic load acting on pavement. 200 loading cycles of each stress stage were applied to the specimens.

\section{Quality control of all tests}

Triplicate tests were performed on each test and the averages of these three tests were reported as the results. The coefficient of variation, CV (ratio of standard deviation to the mean) was less than $10 \%$ in all tests.

\section{TEST RESULTS AND DISCUSSION}

\section{Static triaxial tests}

Static triaxial tests by means of the drained triaxial compression tests were performed to obtain information about the shear strength parameters (c and ø) of 
HCTCRB. These tests also established the failure line of HCTCRB and determined the maximum stress level which could be applied on this material, so that the limited uses of HCTCRB would be known.

Figure 1 shows the static triaxial test results of HCTCRB on the p-q diagram in which the Mohr-Coulomb failure was defined in terms of principle stresses (principle stresses have been written as $\sigma_{1}=$ the major principle stress and $\sigma_{2}=\sigma_{3}=$ the intermediate or minor principle stress). The deviator stress, $q=\left(\sigma_{1}-\sigma_{3}\right)$, was plotted against the mean applied stress, $\mathrm{p}=\left(\sigma_{1}+2 \sigma_{3}\right) / 3$. The results shown in Figure 1 indicate that the Mohr-Coulomb failure envelope (corresponding to the peak stresses) is linear for the stress range tested and has a characteristic in $\mathrm{p}-\mathrm{q}$ stress space: $\mathrm{M}_{\mathrm{p}}=\mathrm{q} / \mathrm{p}=1.723$ with a deviator stress intercept, $\mathrm{q}_{\mathrm{c}}=339 \mathrm{kPa}$. In the conventional Mohr-Coulomb stress space, the properties failure correspond to an internal friction angle $(\phi)$ at a peak strength of $42^{\circ}$ and an apparent cohesion (c) of $177 \mathrm{kPa}$.

The static triaxial test results of HCTCRB show that it exhibits cohesive granular material behavior unlike non-cohesive granular materials such as sands and gravels. Its behavior depends strongly upon both degrees of cohesion and the internal friction angle.

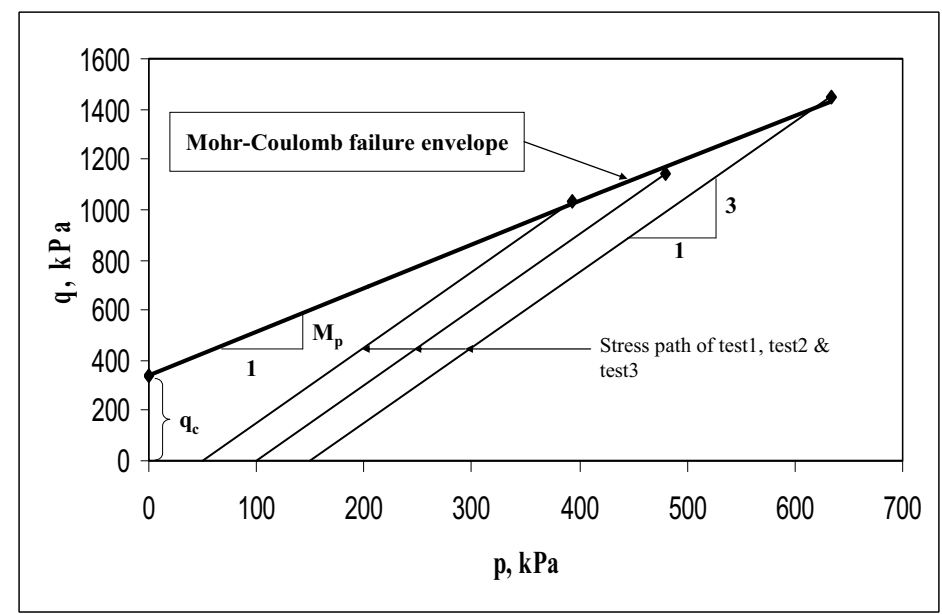

Figure 1 Triaxial test results of HCTCRB in p-q stress spaces.

\section{Resilient modulus tests and permanent deformation test}

The resilient modulus determined from the repeated loading triaxial test is defined as the ratio of the repeated axial deviator stress to the recoverable or resilient axial strain:

$$
M_{r}=\frac{\sigma_{d}}{\varepsilon_{r}}
$$

Where $M_{r}$ is the resilient modulus, $\sigma_{d}$ is the repeated deviator stress (cyclic stress in excess of confining pressure), and $\varepsilon_{\mathrm{r}}$ is the resilient (recoverable) strain in the vertical direction.

Based on the specifications of HCTCRB, the results of the tests, at the value of $100 \% \mathrm{OMC}$ with a 7 -day hydration period and a 28 -day curing time, show the characteristics of HCTCRB and determine the suitable mathematical models of the resilient modulus and the permanent deformation of HCTCRB. 
Figure 2(a) shows the results of the resilient modulus which are plotted against with the bulk stress $\left(\sigma_{1}+\sigma_{2}+\sigma_{3}\right)$. Generally, the resilient modulus is non-linear with respect to the magnitude of applied stresses. Figure 3(a) also shows that the results of the resilient modulus of HCTCRB can be modeled reasonably by using The K-Theta $(\mathrm{K}-\theta)$ model(Hick \& Monismith, 1971). The representative K- $\theta$ model of HCTCRB is exhibited in equation (2).

$$
M_{r}=k_{1} \theta^{k_{2}}=7.684 \theta^{0.591}
$$

Where: $\mathrm{M}_{\mathrm{r}}$ is Resilient modulus in MPa; $\theta$ is bulk Stress $\left(\sigma_{1}+\sigma_{2}+\sigma_{3}\right)$ where $\left(\sigma_{1}=\sigma_{3}\right)$; $\sigma_{1}$ is major principal stress (axial stress); $\sigma_{3}$ is minor principal stress (confining stress); $\mathrm{k}_{1}=7.684$ and $\mathrm{k}_{2}=0.591$ are regression coefficients.

Figure 2(b) shows the typical results of the permanent deformation test in terms of relationship between permanent deformation and loading cycles for HCTCRB. Figure 2(b) also shows the comparison of the measured permanent deformation values and the predicted values for a proposed permanent deformation model of HCTCRB. Figure 3(b) indicates that the permanent deformation can be modeled quite reasonably for HCTCRB by using the model suggested by Sweere, G.T.H from SAMARIS(SAMARIS, 2004). The proposed permanent deformation model of HCTCRB is shown in equation (3).

$$
\varepsilon^{p}=A^{*} N^{B}=573.223 * N^{0.074}
$$

Where: $\varepsilon^{\mathrm{p}}$ is permanent deformation in Micrometers; $\mathrm{A}=573.223$ and $\mathrm{B}=0.074$ are regression constants; and $\mathrm{N}$ is the number of loading cycles

The effect of hydration periods and water added on HCTCRB performance Figure 3 shows all the results of HCTCRB samples of $100 \% \mathrm{OMC}$, $90 \% \mathrm{OMC}$, and 80\%OMC at 7-day, 14-day, and 30-day hydration periods. Resilient modulus values are plotted against loading sequences. There is a slight difference in the resilient modulus characteristics of HCTCRB at all percentages of OMC in 7day, 14-day, and 30-day periods. That means the hydration period and water added in this investigation do not drastically affect the performance of HCTCRB in terms of the resilient modulus characteristics. These characteristics result from the re-treating process before compaction in the HCTCRB- producing method. During the hydration period, a chemical reaction, between cement and water, occurs to generate a cementatious bond. This bond is broken up in the re-treating process. Although a compaction process is performed directly after the re-treating process, the chemical bond, which is significant to the strength of HCTCRB, become difficult to reproduce. The mixture is compacted with the same amount of energy. That is why the resilient modulus characteristics of all samples with diffent conditions of water and hydration periods are slightly different.All HCTCRB samples exhibit the stress-dependency behavior.Based on 65 stress levels, the resilient modulus values of all HCTCRB samples of these conditions are between $300 \mathrm{MPa}$ and $1100 \mathrm{MPa}$. 


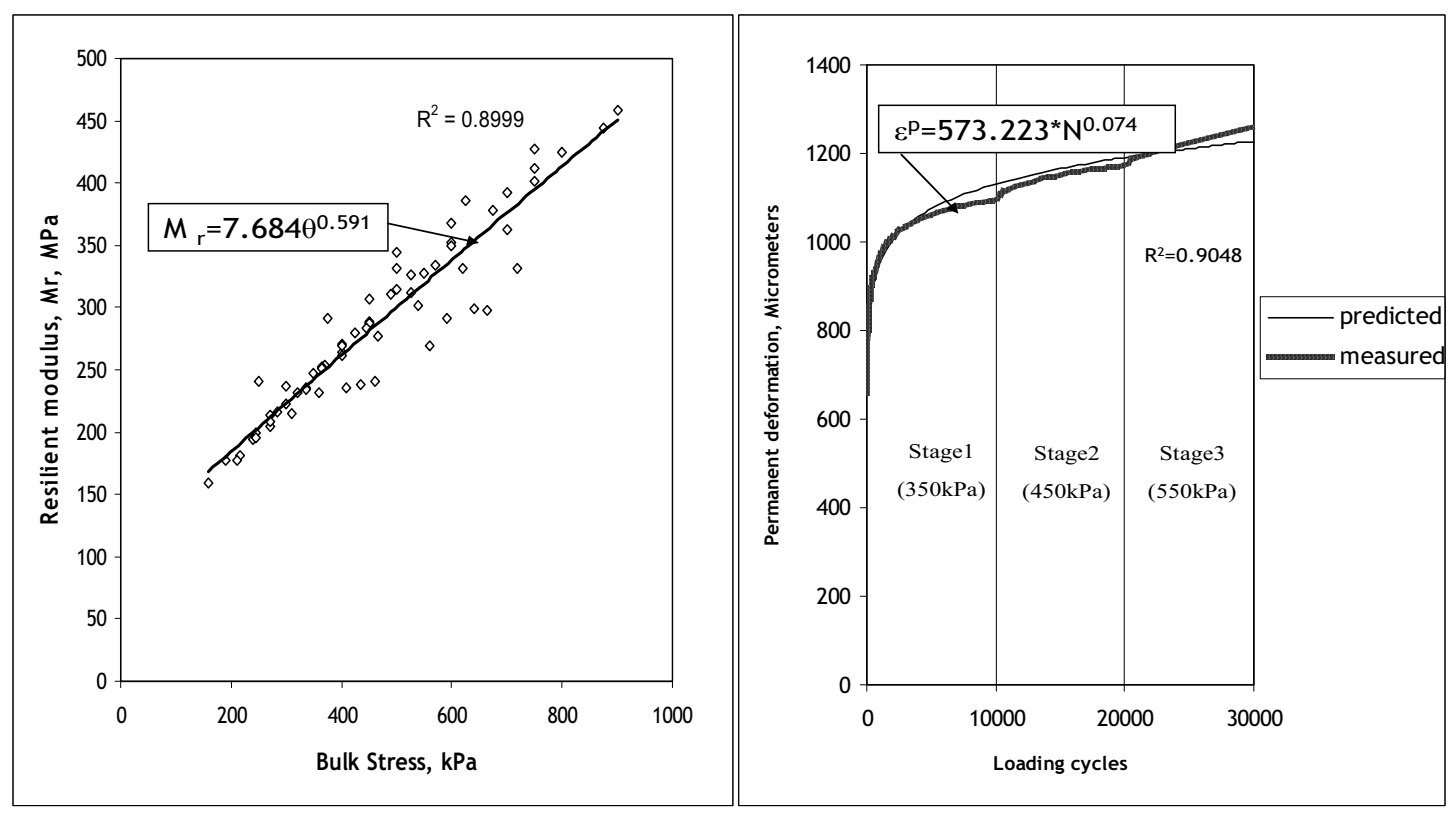

(a)

(b)

Figure 2 The resilient modulus results and permanent deformation results.

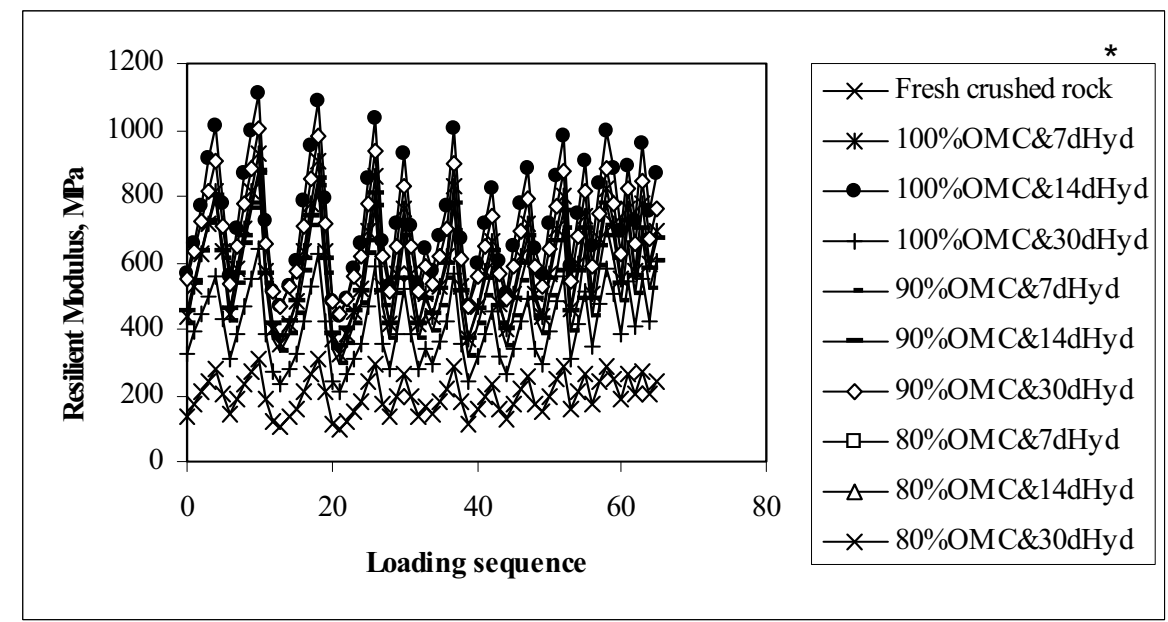

* $x$ OMC\& y dHyd means HCTCRB at $x$ \% OMC water added and y days of hydration period

Figure 3 The resilient modulus results and permanent deformation results.

\section{CONCLUSIONS}

The mechanical behavior of Hydrated Cement Treated Crushed Rock Base (HCTCRB) which is normally used as a base course material in Western Australia was investigated by means of static and repeated loading triaxial tests. The repeated loading triaxial tests were carried out in terms of the resilient modulus test and the permanent deformation test to provide insight into the resilient and permanent 
deformation characteristics of this material under the real traffic load conditions simulated in these tests.

It has been shown that HCTCRB can be characterized as an apparently cohesive granular material which has the cohesion (c) of $177 \mathrm{kPa}$ and the internal friction angle $(\phi)$ of $42^{\circ}$ over the stress range significant for pavement behavior. Based on the Austroads - APRG 00/33 test standard, the resilient modulus characteristics could be modeled using the K- $\theta$ model. The permanent deformation characteristics could be modeled by using the Sweere's model.

The hydration period and water added in this investigation did not drastically much affect the performance of HCTCRB. All HCTCRB samples also show the stress-dependency behavior. Based on the stress stage of this experiment, the resilient modulus values of HCTCRB in this study are in the range of about $300 \mathrm{MPa}$ to 1100 $\mathrm{MPa}$.

\section{REFERENCES}

Australian Standard (1997). Portland and blended cements. 2006(September, 2006, from http://www.saiglobal.com.dbgw.lis.curtin.edu.au).

Austroads (2004). Pavement Design-A Guide to the Structural Design of Road Pavements, Austroad Inc.2004.

Cockburn cement (2006). General Specification (November, 2006, from http://www.cockburncement.com.au).

Hick, R. G. and C. L. Monismith (1971). "Factors influencing the resilient response of granular materials." Highway Research Recond No. 345: 15-31.

Main Roads Western Australia (1997). Dry density/moisture content relationship: modified compaction fine and medium grained soils(December, 2006, from http://www.mainroads.wa.gov.au).

Main Roads Western Australia (2003). Crushed Rock Base Basecourse(December, 2006, from http://www.mainroads.wa.gov.au).

.Main Roads Western Australia (2003). Crushed Rock Base Basecourse(December, 2006, from http://www.mainroads.wa.gov.au).

Main Roads Western Australia (2006). Test Method (Aggregate). (December, 2006, from http://www.mainroads.wa.gov.au).

SAMARIS (2004). Selection and evaluation of models for prediction of permanent deformations of unbound granular materials in road pavement, Sustainable and Advanced MAterials for Road InfraStruture: 55.

Suiker, A. J., E. Selig, et al. (2005). "Static and Cyclic Triaxial Testing of Ballast and Subballast. Journal of Geotechnical and Geoenvironmental Engineering, 131(6), 771-782. Retrieved: June 2005Voung, B. T. and R. Brimble (2000). Austroads Repeated Load Triaxial Test Method-Determination of Permanent Deformation and Resilient Modulus Characteristics of Unbound Granular Materials Under Drained Conditions. APRG DOCUMENT APRG 00/33(MA), Austroads.

Voung, B. T. and R. Brimble (2000). Austroads Repeated Load Triaxial Test Method-Determination of Permanent Deformation and Resilient Modulus Characteristics of Unbound Granular Materials Under Drained Conditions. APRG DOCUMENT APRG 00/33(MA), Austroads 